\title{
TRADUZIR É UM ATO POLÍTICO? ALGUMAS CONSIDERAÇÕES A PARTIR DE WALTER BENJAMIN
}

\author{
IS TRANSLATING A POLITICAL ACT? CONSIDERATIONS DEPARTING FROM WALTER \\ BENJAMIN
}

Isabela Pinho*

\begin{abstract}
RESUMO
O presente artigo tem em vista a reformulação da língua pura no ensaio "A tarefa do tradutor" de Walter Benjamin, com o objetivo de indicar, como apontamento a ser desdobrado, a relação entre tradução, linguagem e política. A tradução concebida não como mera transcrição de uma língua para outra, nem como comunicação do sentido da obra original, mas como afinidade supra-histórica (überhistorischer Verwandtschaft) entre as línguas históricas implica outra experiência da linguagem. É a experiência da comunicabilidade da linguagem para além de seu caráter comunicativo e para além das línguas históricas que ensejará, como apontamento, um questionamento sobre a dimensão política da tradução. Dividido em duas seções "tradução: encontro amoroso entre línguas" e "tradução: para além das barreiras históricas das línguas", este artigo trabalha tanto uma metafórica feminina como uma metafórica política encontradas no ensaio benjaminiano. Para tanto, analiso o fragmento Nähe und Ferne ("Proximidade e afastamento") de Benjamin e apresento algumas questões de $O$ nómos da terra de Carl Schmitt, que abrem para futuros desdobramentos ao final do artigo. PALAVRAS-CHAVE: Tradução. Linguagem. Língua pura. Comunicabilidade. Política.
\end{abstract}

\section{ABSTRACT}

This article aims at unearthing the relationship between Translation, Language and Politics as well as the reformulation of the pure language in Walter Benjamin's essay "The task of the translator". The conception of translation not as mere transcription from one language to another, nor as communication of the meaning of the original oeuvre, but as a transhistorical affinity (überhistorischer Verwandtschaft) between the historical languages indicates another possibility of experiencing language. The experience of the communicability of language itself, beyond its communicative aspect and beyond the historical languages, implies the political dimension of translation. This article aims to present feminine metaphors as well as political metaphors found in Benjamin's essay. In order to do so, I will analyze Benjamin's fragment Nähe und Ferne and some aspects of Carl Schmitt's book The Nomos of the earth in the sections "translation: a lovable encounter between languages" and "translation: beyond the historical frontiers of languages", respectively.

KEYWORDS: Translation. Language. Pure language. Communicability. Politics.

\footnotetext{
*Doutora em Filosofia pela UFRJ. Professora de Filosofia da PUC Rio. E-mail: isabelafpinho@gmail.com.
} 


\section{INTRODUÇÃO}

Por volta de 1915 Walter Benjamin começa a traduzir para o alemão os poemas de Charles Baudelaire. Em 1923 ele publica Tableaux parisiens em edição bilíngue, pela editora Richard Weissbach. Segundo indicações de uma carta ao seu amigo Gerschom Scholem, Benjamin redige o ensaio “A tarefa do tradutor” em 1921 como prefácio para sua tradução. É de supor, portanto, que o próprio trabalho de tradução tenha instigado a necessidade de uma reflexão filosófica acerca da linguagem. Em que consiste a "tarefa do tradutor"? Seria a mera transcrição de uma língua para outra? É preciso adiantar que Benjamin não considera a tradução como mera cópia do original. Ao contrário, o tradutor faz outra experiência não somente de sua língua como também da língua estrangeira, de tal modo que ambas se tornam indiscerníveis em uma outra língua: a língua pura (die reine Sprache).

Posso tentar esclarecer com um exemplo. Acredito ser uma experiência comum entre aqueles que traduzem deparar-se, por vezes, com o esquecimento dos termos da própria língua: comumente a palavra estrangeira nos faz esquecer da própria palavra na língua materna, produzindo uma espécie de estranhamento da própria língua. "Como se diz mesmo...?" De súbito, a palavra cai em nossos lábios: “ah, é isso, é assim que se diz”. O que ocorre no átimo de segundo em que não se está nem no registro da língua materna e nem no registro da língua estrangeira? No limiar entre duas línguas, o tradutor faz a experiência de que há linguagem, faz a experiência da comunicabilidade da linguagem para além de seu aspecto comunicativo.

A distinção entre a comunicabilidade da linguagem e linguagem como comunicação corresponde à distinção entre Medium e Mittel da linguagem feita no ensaio "Sobre a linguagem em geral e sobre a linguagem humana" (1916) de Benjamin. Ambas as palavras significam "meio", com uma diferença: Mittel é um meio para um fim e Medium é um meio em si mesmo. Em sua releitura do Gênesis bíblico, a língua pura é caracterizada como o Medium da linguagem, como a própria comunicabilidade da linguagem, a linguagem paradisíaca com a qual Deus teria criado o mundo e da qual Adão participa ao nomear o mundo; e a língua como comunicação (Mittel) corresponde à linguagem humana, comunicativa, que coincide com a queda do paraíso. Nesse ensaio, a língua pura tem uma dimensão negativa: em todo dito e em todo dizer, ela é o que permanece como não dito, como inefável. 
$\mathrm{Na}$ “Tarefa do tradutor" a língua pura será pensada como o que é visado (das Gemeinte) pelas múltiplas línguas históricas. As múltiplas línguas históricas teriam um parentesco supra-histórico naquilo que visam e querem dizer: a pura língua. A tarefa do tradutor não seria comunicar o sentido da obra original, mas expressar o mais íntimo relacionamento das línguas entre si e o anseio por uma complementação entre as línguas. Como veremos com Benjamin, ao desvincular-se do sentido comunicativo, a tradução indica o fim messiânico da história das línguas. Se as línguas históricas são imprescindíveis para a constituição de uma identidade nacional, ao propor a tarefa do tradutor como ultrapassagem das barreiras e fronteiras entre as línguas, Benjamin estaria pensando a tradução como um ato político?

Seria estranho pensar a tradução como um gesto de tolerância. Traduzir é mais que tolerar, é encontrar, mas esse encontro não é apropriador. Para pensar a relação entre as línguas que pode ter lugar na tradução, divido este artigo em duas seções: "tradução: encontro amoroso entre línguas" e "tradução: para além das barreiras das línguas". Na primeira seção, destaco uma metafórica feminina no ensaio de Benjamin e vou ao fragmento Nähe und Ferne ("Proximidade e afastamento") para pensar o elemento erótico da tradução. Na segunda seção, remeto ao Nómos da terra, de Carl Schmitt, para pensar a apropriação da terra e o estabelecimento de fronteiras como o ato jurídico-político primordial a partir do qual a normatividade jurídica tem lugar: questões que concluem o artigo com uma abertura para desdobramentos futuros. A pergunta sobre a relação entre tradução e política funciona como mote para uma imersão no ensaio de Benjamin e, sobretudo, como desafio para a escrita.

\section{TRADUÇÃO: ENCONTRO AMOROSO ENTRE LÍNGUAS}

Benjamin inicia seu ensaio ao afirmar que assim como nenhuma obra de arte deve levar em consideração o receptor, também a tradução não deve fazê-lo. A má tradução é aquela que se compromete a servir ao leitor tendo em vista "uma transmissão inexata de um conteúdo inessencial” (BENJAMIN, 2011a, p. 102). Em termos parecidos com os do célebre ensaio "Sobre a linguagem em geral e sobre a linguagem humana", a má tradução é aquela que tem em vista a comunicação de conteúdos inessenciais à própria obra. Por "conteúdos inessenciais" deve-se entender a transmissão de elementos externos à própria língua: a informação como objeto a ser transmitido através da língua. Para Benjamin, o que o tradutor pode restituir do original não é um conteúdo informativo, mas sim aquilo que, na obra, não é 
comunicável: o inapreensível (Unfassbare), o misterioso (Geheimnsvolle), e o "poético" (Dichterische) (BENJAMIN, 2011a, p. 102).

Desse modo, a tradução é concebida como um desdobramento do original. E é graças ao que Benjamin chama de traduzibilidade (Übersetzbarkeit) do original - o fato de que uma obra admite tradução ou até mesmo a exige - que, ambos, tradução e original, se encontram em íntima conexão (nächsten Zusammenhang). A íntima conexão entre original e obra é chamada por Benjamin de conexão de vida (Zusammenhang des Lebens). Ele dirá que, da mesma forma como as manifestações da vida estão ligadas ao ser vivo, sem nada significarem para ele, o mesmo ocorre na relação entre a tradução e o original. Na verdade, para Benjamin, a tradução deriva não tanto da vida do original como de sua "sobrevida" (Überleben) e de sua "pervivência" (Fortleben), sua sobrevivência e seu continuar (Fort) a viver (leben) na história da cultura. A vida, sobrevida ou "pervivência" das obras, deve ser entendida em sentido literal, pois, para Benjamin, vida é tudo aquilo que possui história, e não, meramente, uma corporeidade orgânica e animal. ${ }^{1}$

A tradução deve sua existência à "pervivência" da obra e, nela, o original alcança "seu mais tardio e mais abrangente desdobramento" (BENJAMIN, 2011a, p. 105). Esse desdobramento é determinado por uma finalidade (Zweckmässigkeit). Mas essa finalidade, ou esse processo de adequação a um fim, a um propósito (Zweck), consiste em “expressar o mais íntimo relacionamento das línguas entre si” (p. 106). Benjamin diz que a tradução pode apresentar (darstellen) a "relação oculta" (verbogene Verhältnis) entre as diversas línguas. Essa apresentação (Darstellung) de um objeto (a relação oculta entre as línguas) "pelo germe de sua produção (den keim seiner Herstellung)" (pela própria linguagem) é um modo peculiar de apresentação, que pode ser encontrado na vida linguageira (spralichen Lebens). Isso quer dizer que raramente em outro âmbito da vida que não seja a linguagem um objeto e sua forma de apresentação coincidem: a relação oculta entre as diversas línguas (o objeto) se apresenta na própria linguagem (na própria forma de apresentação desse objeto, que é a linguagem). Para Benjamin (p. 106, 107), a íntima relação entre as diversas línguas é de uma convergência bastante particular: "consiste no fato de que as línguas não são estranhas umas às outras, sendo a priori - e abstraindo de todas as ligações históricas - afins naquilo que querem dizer".

\footnotetext{
${ }^{1}$ Considero importante ressaltar que a concepção de uma continuação da vida das obras para além da vida de seu autor e de sua produção remete à teoria da crítica e da tradução do primeiro romantismo alemão, objeto da tese de doutorado de Benjamin. Ver Benjamin (1993). A obra de arte será considerada um médium-de-reflexão, ou seja, obra de arte é tudo aquilo que pode ser desdobrado, e a crítica é desdobramento.
} 
A afinidade (Verwandtschaft $)^{2}$ entre as línguas, que se pode verificar na tradução, não é, no entanto, do âmbito da reprodução do sentido do original. A relação entre original e tradução não é da ordem de uma relação entre original e cópia, isto é, da reprodução do original: "se a afinidade [Verwandtschaft] entre as línguas se anuncia na tradução, isso ocorre de modo distinto da vaga semelhança [̈̈nlichkeit] entre reprodução e original” (BENJAMIN, 2011a, p. 108) Isso porque o original se modifica, se renova e se transforma em sua "pervivência", em seu continuar a viver, nas traduções: "na sua pervivência (que não mereceria tal nome, se não fosse transformação e renovação de tudo aquilo que vive), o original se modifica" (p. 107). Portanto, a relação entre original e tradução não é de uma identidade de proveniência, pois tanto a linguagem do original quanto a linguagem da tradução se modificam ao longo do tempo: "assim como o tom e significação das grandes obras poéticas se transformam completamente ao longo dos séculos, assim também a língua materna do tradutor [die Muttersprache des Übersetzers] se transforma" (p. 108).

Essas modificações da obra original, como, por exemplo, palavras de uso corrente que se tornam arcaicas ou palavras de cunho poético que se tornam prosaicas, devem ser procuradas na própria vida da linguagem, em seu processo histórico, e não na subjetividade dos pósteros:

\begin{abstract}
procurar o essencial de tais mudanças (bem como das igualmente constantes modificações do sentido) na subjetividade dos pósteros, em vez de buscá-lo na vida mais íntima da linguagem e de suas obras, seria, mesmo se admitirmos o mais tosco psicologismo, confundir causa e essência de um objeto; expresso de modo mais rigoroso: seria negar um dos processos históricos mais poderosos e produtivos por impotência de pensamento. (BENJAMIN, 2011a, p. 108).
\end{abstract}

Com efeito, Benjamin (2011a, p. 108) afirma que compete sobretudo à tradução atentar para a "maturação póstuma da palavra estrangeira", pois se a palavra do poeta perdura em sua língua materna, em sua Muttersprache, é na tradução que as transformações da língua do original são atualizadas e renovadas. Poderia ser uma alusão à associação histórica entre língua e maternidade (o fato de que uma língua é dita materna) aquilo a que Benjamin se refere ao falar das dores do parto da própria tradução? Ele diz:

\footnotetext{
${ }^{2}$ Observo que a palavra Verwandtschaft pode ser traduzida tanto por afinidade quanto por parentesco, incluindo as relações de consanguinidade. Benjamin (2009) também trabalha essa questão em "Sobre as afinidades eletivas [die Wahlverwandtschaften] de Goethe".
} 
tão longe a tradução está de ser a equação estéril [die taube Gleichung] entre duas línguas mortas que, precisamente a ela, dentre todas as formas, a ela mais propriamente compete atentar para aquela maturação póstuma da palavra estrangeira, e para as dores do parto de sua própria palavra [auf die Wehen des eigenen zu merken]. (BENJAMIN, 2011a, p. 108).

Nesse trecho, há uma associação entre linguagem e feminino: a tradução não é uma equação estéril entre duas línguas mortas; a ela compete atentar para o "continuar a amadurecer" (Nachreife) da palavra estrangeira e para as dores do parto de sua própria palavra. ${ }^{3}$ Essa metafórica feminina possivelmente remete à própria concepção da língua como algo vivo, pois na associação histórica entre a mulher, a mãe e o feminino, a mulher aparece como aquela que porta e produz a vida ao dar à luz. Talvez daí provenha a potência do feminino, sua fertilidade, sua associação à capacidade de renovação. É curioso observar que na tradição judaica a abolição da Torá, ou seja, da lei, da tradição e dos ritos, se dá através das “dores do parto” do messias. Nas palavras do cabalista do século XVI, Rabi Judá:

parece que o velho modo de ser será arruinado no mundo, produzindo diferentes coisas; e, assim como haverá uma mudança por causa da ruína do antigo mundo, haverá uma diferença no mundo por causa do novo que surgiu; assim como cada ruína opera uma mudança, cada ser opera uma mudança no mundo - e a isto chamam-se as dores de parto do messias. [...] Neste sentido, as dores messiânicas aparecerão, tal qual uma mulher em trabalho de parto, por causa da entrada no mundo do novo ser e da criança. (SCHOLEM, 1995, p. 65). ${ }^{4}$

Mais adiante, Benjamin se referirá ao fim messiânico de todas as línguas. Ou seja, a possibilidade de renovação e mudança no mundo tem uma potência feminina, em sua ambiguidade de mulher e mãe.

Se a afinidade entre as línguas da tradução e do original não é da ordem da vaga - e estéril - semelhança entre reprodução e original, Benjamin dirá que essa afinidade é de uma outra ordem: as línguas são afins naquilo que querem dizer - a pura língua. Em suas palavras:

toda afinidade supra-histórica entre as línguas históricas [alle überhistorische Verwandtschaft der Sprachen darin] repousa sobre o fato de que, em cada uma delas, tomada como um todo, uma só e a mesma coisa é visada [gemeint ist]; algo que, no entanto, não pode ser alcançado por nenhuma delas, isoladamente, mas somente na totalidade de suas intenções reciprocamente complementares: a pura língua [die reine Sprache]. (BENJAMIN, 2011a, p. 109).

\footnotetext{
${ }^{3}$ Para mais sobre a relação entre linguagem e feminino em Benjamin, ver Pinho (2019, p.102-120), (2018, p. 2036) e (2014, p. 1-141).

${ }^{4}$ Agradeço a Pedro Oliveira pela referência.
} 
Se, por um lado, as línguas estrangeiras se diferenciam em seus elementos isolados, como no caso das diferentes palavras, nexos sintáticos e frases, por outro lado, elas se complementam naquilo que querem dizer: a língua pura. À diferença e semelhança entre as línguas correspondem o modo de visar (die art des Meinens) e o visado (das Gemeinte), respectivamente. Benjamin diz ser importante distinguir, na intenção, o visado (aquilo que se quer dizer) do modo de visar (a maneira de dizer). Dessa forma, as palavras "Brot", "pain" e "pão" são maneiras diferentes de dizer o mesmo objeto visado nas línguas alemã, francesa e portuguesa, respectivamente. Mas a língua pura consiste na harmonia de todos os modos de visar, ou seja, no "modo de visar convergindo para o que é visado" (BENJAMIN, 2011a, p. 109). Se, nas línguas isoladas, particulares, o visado nunca se encontra de maneira autônoma, pois é dito de maneiras diferentes, é da harmonia de todos os modos de visar que o visado consegue emergir como língua pura. "Nas línguas tomadas isoladamente, aquilo que é visado nunca se encontra de maneira relativamente autônoma, como nas palavras e frases tomadas isoladamente; encontra-se em constante transformação, até que da harmonia de todos aqueles modos de visar, ele [o visado] consiga emergir como língua pura.” (BENJAMIN, 2011a, p. 109).

Não é por acaso que Benjamin evoca, nesse momento do ensaio, o fim messiânico da história das línguas e diz que, chegado esse fim, caberá à tradução pôr à prova "aquele sagrado crescimento das línguas" (BENJAMIN, 2011a, p. 110). Pois, também para a tradução vale o preceito bíblico "en arché en hó lógos", no princípio era o Verbo, sobre o qual Benjamin se debruça no ensaio "Sobre a linguagem". Isso quer dizer que na tradução o elemento sagrado, oculto e não comunicativo (o Medium da linguagem) de todas as línguas pode, ainda que de modo provisório, tornar-se presente: "toda tradução é apenas um modo algo provisório de lidar com a estranheza [Fremdheit] das línguas" (BENJAMIN, 2011a, p. 110). Para Benjamin, a tradução é superior ao original, pois se dirige a "um estágio último, definitivo e decisivo de toda construção de linguagem”. Isso porque na tradução, “o original cresce e se alça a uma atmosfera por assim dizer mais elevada e mais pura da língua” (p. 110). Essa esfera mais pura da língua, ou esse núcleo essencial que não pode ser traduzido, é o que resta em termos de informação do texto original.

Benjamin nos diz que a tradução transplanta o original para um domínio mais definitivo da língua, mais atualizado, mais desdobrado. Esse domínio mais definitivo pode ser pensado de acordo com uma analogia: se, no original, teor (Gehalt) e língua são como a unidade entre casca e fruto, na tradução "a língua recobre seu teor em amplas pregas, como 
um manto real" (BENJAMIN, 2011a, p. 111). No caso da obra original, a língua recobre adequadamente seu teor formando uma unidade. No caso da tradução, há uma inadequação entre a língua e o teor comparada às amplas pregas de um manto real, este podendo indicar as várias camadas de linguagem que recobrem o teor da obra. No caso da tradução, há uma "poderosa e estranha" inadequação entre língua e teor.

É nessa fratura entre as línguas, nessa fronteira, que a tradução se coloca. Assim, o que está em questão na tarefa do tradutor "é a integração das várias línguas em uma única, verdadeira" (BENJAMIN, 2011a, p. 112). Essa língua é aquela na qual "as línguas coincidem entre si, completas e reconciliadas no seu modo de visar" (p. 113). Para Benjamin, essa língua, que se encontra oculta nas traduções, e cujo "pressentimento e descrição constituem a única perfeição que o filósofo [e também o tradutor] pode esperar" (p. 113), é a verdadeira língua. Mas essa língua verdadeira, em que os modos de visar (as diferentes maneiras de dizer das diferentes línguas históricas) coincidem e se reconciliam, tem uma materialidade, que pode ser pensada a partir da citação que Benjamin faz de um trecho de Crise do verso, de Mallarmé:

as línguas imperfeitas nisso que muitas, falta a suprema: pensar sendo escrever sem acessórios, nem sussurro, mas tácita ainda a imortal palavra, a diversidade, sobre a terra, dos idiomas impede alguém de proferir as palavras que, senão se encontrariam, por uma só punção, ela mesma materialmente a verdade. (BENJAMIN, 2011a, p. 113).

De acordo com o trecho, a língua suprema, de difícil acesso devido à diversidade dos idiomas, é uma língua em que pensamento é escrita: escrita sem acessórios, nem sussurros, nem silêncios; escrita de palavras que se encontrariam, materialmente, por uma só punção (une frappe unique). É interessante observar que o polissêmico verbo "frapper", em língua francesa, também significa a ação de compor ou escrever um texto em um teclado, podendo remeter à materialidade da letra, elemento comum entre as diferentes palavras das diferentes línguas. Na letra, substrato material, as palavras se encontrariam por uma só punção, por um choque de contato, um toque fugaz.

Nesse ponto, Benjamin atenta para a obscuridade que pode ter uma tradução em que a reprodução do sentido cessa de ser determinante, mas, ainda assim, se posiciona contra os tradicionais preceitos que norteiam as discussões acerca da tradução: contra a liberdade do tradutor na reprodução do sentido e a fidelidade à palavra no âmbito semântico, Benjamin propõe justamente a literalidade com relação à sintaxe. 
Para Benjamin, a fidelidade na tradução de cada palavra isolada não é capaz de reproduzir o sentido que ela possui no original, pois o sentido não se esgota no visado, mas "adquire essa significação precisamente pela maneira como o visado se liga, em cada palavra específica, ao modo de visar" (BENJAMIN, 2011a, p. 114). Isso quer dizer que "as palavras carregam uma tonalidade afetiva [die Worte einen Gefühlston mit sich führen]". Ou seja, do ponto de vista literário, há uma relação não de arbitrariedade, mas de afecção entre aquilo que se quer dizer (o visado) e a maneira como se diz (o modo de visar). Contra a "indisciplinada liberdade dos maus tradutores”, Benjamin advoga por uma tradução que não seja da ordem da palavra significante como abertura para diversas significações, em que o tradutor escolhe qual sentido funciona melhor, qual sentido ele prefere, mas que seja da ordem da materialidade da letra. Como nos diz Benjamin: "a exigência de literalidade não pode ser derivada do interesse na manutenção do sentido" (p. 114).

Ao contrário, Benjamin, com uma bela analogia, diz que assim como os cacos de um vaso, para serem recompostos, devem encaixar-se nos mínimos detalhes, mas sem serem iguais, a tradução deve,

em vez de procurar assemelhar-se ao sentido do original, conformar-se amorosamente e nos mínimos detalhes, em sua própria língua, ao modo de visar do original, fazendo com que ambos sejam reconhecidos como fragmentos de uma língua maior, como cacos são fragmentos de um vaso. (BENJAMIN, 2011a, p. 115).

Tanto original quanto tradução aparecem como cacos ou fragmentos de uma língua maior. Nesse ponto, gostaria de chamar atenção para o advérbio "amorosamente" (liebend) com o qual Benjamin qualifica a conformação da língua da tradução ao modo de visar da língua do original: as línguas da tradução e do original devem conformar-se "amorosamente". De que modo? Em um fragmento intitulado "Nähe und Ferne", "Proximidade e afastamento", datado possivelmente entre os anos 1922-1925, Benjamin caracteriza o amor, Eros, como da ordem de uma proximidade, e ao mesmo tempo, de uma distância:

[...] vida de Eros se acende graças ao longínquo. Mas de outro lado existe um parentesco entre proximidade e sexualidade. [...] Proximidade e distância são, aliás, não menos determinantes para o sonho quanto para a erótica. [Das Leben des Eros entzündet sich an der Ferne. Andererseits findet eine Verwandtschaft zwischen Nähe und Sexualität statt [...] Nähe (und Ferne) sind übrigens für den Traum nicht 
weniger bestimmend als für Erotik]. (BENJAMIN, 1972, p. 83-85, tradução de Gagnebin). ${ }^{5}$

Gostaria de remeter a uma observação filológica feita por Jeanne-Marie Gagnebin no instigante artigo A questão de "Eros" na obra de Benjamin. Gagnebin atenta para o fato de que, em língua alemã, parece haver poucas palavras para dizer "proximidade" e "próximo", enquanto que para "distância" há muitas. Por exemplo, "temos Distanz, do francês distance, Abstand, recuo, Ferne, o longínquo, afastado, Entfernung, afastamento" (GAGNEBIN, 2008, p. 40). Como argumenta Gagnebin, a raiz fern indica distância, mas não uma distância que seja objetiva e mensurável. O longínquo (fern) não indica uma distância de um objeto que pode ser apropriado, mas, ao contrário, indica a possibilidade de aproximação a um objeto determinado que se quer possuir sem poder fazê-lo. No longínquo, "trata-se de uma distância que a ação instrumental do sujeito não consegue abolir" (GAGNEBIN, 2008, p. 40). Posso me aproximar do objeto distante, sem, no entanto, poder possuí-lo. De certa maneira, essa relação entre o longínquo e o erótico já está posta em questão através da fala de Diotima, em $O$ Banquete de Platão, diálogo citado por Benjamin diversas vezes nesse fragmento e também, posteriormente, no prefácio à Origem do drama barroco alemão. ${ }^{6}$ É Diotima de Mantineia quem instrui Sócrates nas questões de Amor (Eros). No Banquete, Amor, concebido como um Daimon (um gênio), só pode desejar aquilo que não tem, ou seja, aquilo de que é carente: "é uma necessidade que seja assim, o que deseja, deseja aquilo de que é carente, sem o que não deseja, se não for carente" (PLATÃO, 1972, 220b). Desprovido de qualquer qualidade, nem pobre nem feio, nem belo nem rico, nem sábio nem ignorante, Eros deseja o que não tem, pois se o tivesse, não poderia desejá-lo. É a essa relação entre longínquo e desejo erótico que Benjamin se refere aqui.

O distante que constitui o erótico remete, então, à impossibilidade de apropriação do objeto desejado e "reforça a ideia de que o desejo, Eros, se nutre da liberdade do outro em oposição às possibilidades de tomada de posse do eu" (GAGNEBIN, 2008, p. 41). Entretanto, como Benjamin ressalta no início desse fragmento, não há sexualidade nem sexo sem uma

\footnotetext{
${ }^{5}$ Não tratarei, aqui, da questão do sonho, mas segundo indicação de Gagnebin, Benjamin teria escrito esse fragmento influenciado pela leitura dos ensaios Vom Traumbewussttsein (Da consciência do sonho, 1914) e Von Kosmogonischen Eros (Do Eros cosmogônico, 1922) de Ludwig Klages. O que interessa a Benjamin na obra de Klages, segundo Gagnebin (2008, p. 39), é "a relação que este estabelece entre uma teoria do sonho, da imagem onírica e da imagem em geral com a dialética da distância e da proximidade".

${ }^{6}$ Sobre A origem do drama barroco alemão, conferir a seção "Belo filosófico", "Prefácio epistemológicocrítico", 2004, p. 52.
} 
extrema proximidade. Desse modo, há em Eros uma tensão entre proximidade e distância, e essa tensão é remetida à mulher, comumente representada na cultura como objeto de desejo:

[...] na mulher amada, as forças do longínquo aparecem próximas ao homem. Desta maneira, proximidade e distância são os polos na vida de Eros; por isso presença e separação são decisivas no amor [in der Geliebten erscheinen dem Manne die Kräfte der Ferne nah. Dergestalt sind Nähe und Ferne die Pole im Leben des Eros: daher ist Gegenwart und Trennung in der Liebe entscheidend]. ${ }^{7}$ (BENJAMIN, 1972, p. 86).

As forças do longínquo (die Kräfte der Ferne) brilham (erscheinen) na mulher amada sem que ela possa jamais ser possuída. Proximidade e distância se confundem em Eros fazendo com que o próximo não constitua mais uma vizinhança costumeira e nem o longínquo constitua uma distância inacessível, mas, como diz Gagnebin (2008, p. 41), "eles se transformam reciprocamente e se intensificam quando a proximidade se torna o lugar privilegiado da manifestação do longínquo". Assim, quando Benjamin diz que as línguas da tradução e do original devem conformar-se amorosamente, devemos ter em vista essa proximidade distante ou essa distância próxima, constitutiva de Eros. É o que Benjamin apresenta numa comparação:

\begin{abstract}
Da mesma forma como a tangente toca a circunferência de maneira fugidia e em um ponto apenas, sendo esse contato, e não o ponto, que determina a lei segundo a qual ela continua sua via reta para o infinito, a tradução toca fugazmente, e apenas no ponto infinitamente pequeno do sentido do original, para perseguir, segundo a lei da fidelidade, sua própria via no interior da liberdade do movimento da língua. (BENJAMIN, 2011a, p. 117).
\end{abstract}

Esse contato fugaz, ao mesmo tempo próximo e distante, entre a língua do original e a língua da tradução é da ordem da literalidade das palavras, para além do caráter comunicativo da frase: "a frase constitui o muro que se ergue diante da língua do original e a literalidade sua arcada" (BENJAMIN, 2011a, p. 115). A literalidade na transposição da sintaxe funciona, então, de maneira horizontal, para além do muro da frase, como o ponto em que as línguas se encontram, se tocam, amorosamente. A fidelidade da tradução é garantida pela literalidade. A liberdade é da ordem do movimento da própria língua e não da ordem da escolha de palavras por parte do tradutor em nome da fidelidade na reprodução do sentido e da fidelidade à palavra. A intenção da tradução não se dá enquanto reprodução do sentido, mas "enquanto harmonia, complemento da língua na qual se comunica” (p. 115). Como nos diz Benjamin, a

\footnotetext{
${ }^{7}$ Tradução de Gagnebin (2008, p. 41), “A questão de Eros na obra de Benjamin”.
} 
tradução "deve, em larga medida, abstrair do sentido, da intenção de comunicar algo, sendolhe o original essencial apenas pelo fato de já ter eliminado para o tradutor e sua obra o esforço e a ordem necessários à obrigação de comunicar” (p. 115). Por isso, para Benjamin, o melhor elogio que uma tradução pode receber é mostrar que se expressa na obra "o grande anseio por uma complementação entre as línguas” (p. 115). Essa complementação, garantida pela literalidade, se dá de maneira transparente: "a verdadeira tradução é transparente [durchscheinend], não encobre o original, não o tira da luz; ela faz com que a pura língua [die reine Sprache], como que fortalecida por seu próprio meio [Medium], recaia ainda mais sobre o original” (p. 115). Essa transparência da língua pura é garantida pela literalidade para além do sentido e da comunicação.

\section{TRADUÇÃO: ALÉM DAS BARREIRAS DAS LÍNGUAS}

Em uma referência ao encontro amoroso entre as diversas línguas como da ordem de uma tensão entre proximidade e distância, Benjamin (2011a, p. 116) afirma que "resta, para além de qualquer aspecto comunicativo" das línguas, "em extrema proximidade e, no entanto, infinitamente longe [nah und doch unendlich fern] [...] um elemento último, decisivo". Ou seja, se é possível considerar o sentido de uma composição de linguagem (sprachliche Gebilde) como sendo idêntico ao sentido de sua comunicação, resta, no entanto, um elemento último, ao mesmo tempo próximo e distante: o núcleo não comunicável da pura língua. Nas palavras de Benjamin (2011a, p. 116):

\footnotetext{
Resta em todas as línguas e em suas composições [Gebilden], afora o elemento comunicável, um elemento não comunicável [ein Nicht-Mitteilbares], um elemento que - dependendo do contexto em que se encontra - é simbolizante ou simbolizado. Simbolizante apenas nas composições finitas das línguas [in den endlichen Gebilden der Sprachen]; simbolizado, porém, no próprio devir das línguas [im Werden der Sprachen selbst]. E o que busca apresentar-se, e mesmo, constituir-se no devir das línguas é aquele núcleo da pura língua [kern der reinen Sprache].
}

Em primeiro lugar, é importante ressaltar que o termo "Gebilde", encontrado em "sprachliche Gebilde" ("composição de linguagem") é composto pelo verbo "bilden", que significa plasmar, dar forma, e remete à necessidade do limite, da borda para a existência de uma obra. No trecho acima, o núcleo não comunicável da pura língua se encontra nas composições das diversas línguas finitas, as línguas históricas, como simbolizante, ao passo que se encontra como simbolizado no devir das línguas em geral, na vida da linguagem em 
sua abrangência: "se esse núcleo [...] está presente na vida como o próprio simbolizado, nas composições ele reside somente como simbolizante" (BENJAMIN, 2011a, p. 116). Seguindo esse raciocínio, Benjamin reitera que a língua pura está vinculada nas línguas apenas ao linguístico e a suas transformações [Sprachliches und dessen Wandlungen], ao passo que "nas composições [in den Gebilden] ela é atravessada pelo sentido pesado e alheio [schweren und fremden Sinn]" (p. 116). Mas a tarefa do tradutor é desvincular (entbinden) a pura língua desse sentido pesado e alheio (von diesem sie zu entbinden) que constitui as línguas históricas: "transformar o simbolizante no próprio simbolizado, recobrar a pura língua [die reine Sprache] plasmada no movimento da linguagem" (p. 116).

Cabe observar que a palavra "entbinden", traduzida por "desvincular", também significa dar à luz, trazer à luz. Assim, eine Frau entbindet, eine Frau bringt ein Kind zur Welt traduz-se por “uma mulher traz à luz, uma mulher traz uma criança ao mundo”. Já em eine Frau wird von einem Kind entbunden tem-se a tradução "uma mulher foi separada do filho", o que quer dizer que, ao trazer à luz seu filho, foi separada dele. Assim como a mãe desvincula-se do seu filho no nascimento, a tarefa do tradutor seria dar à luz a pura língua em sua própria, desvinculando-se do sentido comunicativo. Nesse momento, a fronteira entre as línguas históricas é ultrapassada, e o simbolizante, constitutivo delas, transforma-se no próprio simbolizado, na língua pura, que é o que elas querem dizer.

Mas essa língua pura não quer dizer mais nada e não significa mais nada:

No interior dessa pura língua que nada mais visa e que nada mais expressa [die nichts mehr meint und nichts mehr ausdrückt] - mas que, enquanto inexpressiva palavra criadora [ausdrucksloses und schöpferisches Wort], é o visado em todas as línguas -, toda comunicação [alle Mitteilung], todo sentido [alle Sinn] e toda intenção [alle Intention] atingem finalmente um mesmo estrato, no qual estão destinadas a extinguir-se. (BENJAMIN, 2011a, p. 116).

Todas as línguas querem dizer a palavra que não quer dizer mais nada, que nada mais expressa, e que nada mais comunica. A língua pura é caracterizada como uma palavra que, ao mesmo tempo em que nada expressa e nada comunica, é, no entanto, criadora (Schöpferisches). Como pensar uma palavra ao mesmo tempo criadora e inexpressiva? A língua pura é inexpressiva porque não funciona como um instrumento para comunicação, não expressa nada através de si mesma, sendo ao mesmo tempo criadora porque diz a própria dizibilidade da linguagem, indica que há linguagem. 
Vimos que o tradutor acessa essa pura língua por meio da literalidade, pois se a frase constitui o muro (die Mauer) que se ergue diante da língua do original, a literalidade é sua arcada. Gostaria de pensar essa horizontalidade evocada pela imagem de uma arcada, e que é da ordem da letra, como possibilidade de ultrapassagem das barreiras entre as diferentes línguas históricas. Benjamin (2011a, p. 117) comenta as barreiras e fronteiras que são ultrapassadas na tradução:

A tarefa do tradutor é redimir, na própria, a pura língua, exilada na estrangeira, liberar a língua do cativeiro da obra por meio da recriação [Umdichtung]. Em nome da pura língua, o tradutor rompe as barreiras apodrecidas [morsche Schranken] da sua própria língua: Lutero, Voss, Hölderlin, George ampliaram as fronteiras [die Grenzen] do alemão.

"Exílio", "cativeiro", "barreiras apodrecidas", "fronteiras": essas palavras remetem à dimensão política não somente da tradução como também da linguagem. De fato, quando Benjamin afirma que a língua pura ultrapassa as barreiras, as fronteiras, das diferentes línguas históricas, essa significação política da linguagem parece evidente. Assim como as línguas são imprescindíveis para a construção de uma identidade nacional, também o estabelecimento de fronteiras foi imprescindível para a constituição dos territórios nacionais e, portanto, para o estabelecimento do que se chama "soberania nacional". Para o jurista alemão Carl Schmitt, em Nómos da terra, a apropriação ou a conquista da terra é o ato jurídico fundamental a partir do qual a própria criação do âmbito jurídico-normativo se dá. Primeiramente, é preciso estabelecer fronteiras e divisões em determinado território, para que, em seguida, se estabeleça o ordenamento jurídico-normativo. Nas palavras de Schmitt (2006, p. 327-328):

[...] cada um desses três processos - apropriação [nehmen], distribuição [teilen], e produção [weiden] - é parte e parcela da história das ordens legais e sociais [...]. Antes de toda ordem legal, econômica, e social, antes de toda teoria legal, econômica, ou social, estão estas questões elementares: onde e como foi apropriado? Onde e como foi dividido? Onde e como foi produzido?.

De acordo com Schmitt, o termo "nomos", palavra grega para lei, indica a ordenação espacial original para o estabelecimento de toda e qualquer ordem jurídica. Nomos indica que o direito está objetivamente enraizado na apropriação da terra. É imprescindível ressaltar que a constituição jurídica de um nomos, ou seja, a apropriação jurídica do espaço, tem por pressuposto a capacidade de nomear: "uma apropriação da terra é constituída apenas se o apropriador for capaz de dar um nome à terra" (SCHMITT, 2006, p. 348). Nesse ponto, 
destaco que o termo alemão Landnahme (apropriação da terra) contém o termo Nahme, antiga grafia do termo Name (nome). Nomear e constituir uma ordem jurídica são atos similares, pois implicam uma apropriação. Exemplos históricos, surpreendentemente ainda frequentes, são a imposição do nome do marido à mulher, que é "tomada em casamento", ou o patronímico imposto à criança no momento de seu nascimento. ${ }^{8}$

Quando Benjamin (2011c, p. 69), em "Sobre a linguagem", constata uma origem mítica do direito na ordem da nomeação deve-se ter em vista essa origem jurídica que ao mesmo tempo em que nomeia se apropria do espaço nomeado. Em "Para uma crítica da violência" (1921), Benjamin não somente se refere ao estabelecimento de fronteiras como o fenômeno originário da violência instauradora do direito em geral (chamada de violência mítica), como também afirma que a violência que pode destituir o direito (chamada de violência divina) aniquila fronteiras. Nas palavras de Benjamin (2011b, p. 148-150): "se a violência mítica é instauradora do direito, a violência divina é aniquiladora do direito; se a primeira estabelece fronteiras [setzt jene Grenzen]; a segunda aniquila sem limites [so vernichtet diese grenzenlos]". Como conceber, então, uma nomeação sem apropriação? É o que está em questão na língua pura benjaminiana.

Se, por um lado, no ensaio de 1916 Benjamin enfatiza a perda da experiência da comunicabilidade da linguagem (Medium) em detrimento de seu caráter comunicativo (Mittel), que se dá com a queda do paraíso, no ensaio de 1921, por outro lado, o enfoque é posto sobre esse fim que todas as línguas históricas almejam alcançar: a língua pura que não quer dizer nada e nada mais expressa. Em Benjamin, a língua pura constitui o parentesco supra-histórico das diferentes línguas históricas. Por meio de uma citação do filósofo e escritor alemão Rudolf Pannwitz (1881 - 1969), ${ }^{9}$ Benjamin (2011a, p. 118) afirma que é preciso "deixar-se abalar violentamente pela língua estrangeira":

Nossas traduções (mesmo as melhores) partem de um falso princípio, querem
germanizar o sânscrito, o grego, o inglês, ao invés de sanscritizar, grecizar,
anglicizar o alemão. Elas possuem um respeito muito maior diante dos próprios usos
linguísticos do que diante do espírito da obra estrangeira [...] o erro fundamental de
quem traduz é conservar o estado fortuito da sua própria língua, ao invés de deixar-
se abalar violentamente pela língua estrangeira. sobretudo quando traduz de uma
língua muito distante ele deve remontar aos elementos últimos da língua mesma

\footnotetext{
${ }^{8}$ Agradeço novamente a Pedro Oliveira pela referência.

${ }^{9}$ A citação se encontra em A crise da cultura europeia (1917). De acordo com a nota da editora de "A Tarefa do tradutor", Pannwitz ignora propositadamente, em muitas de suas obras, as maiúsculas e as vírgulas. (BENJAMIN, 2011a, p. 117).
} 
onde palavra [Wort] imagem [Bild] e som [Ton] se tornam um só ele tem de ampliar e aprofundar sua língua por meio da língua estrangeira.

Para além das fronteiras das línguas é preciso "ampliar e aprofundar sua língua por meio da estrangeira" e "deixar-se abalar pela língua estrangeira". A Língua pura, como a mulher amada do fragmento "Proximidade e afastamento", não pode ser possuída, mas acessada provisoriamente.

\section{CONCLUSÃO}

A tarefa do tradutor (Die Aufgabe des Übersetzers) - dizer a língua pura que todas as línguas particulares querem dizer - deve ser compreendida a partir do próprio termo alemão para "tarefa": Aufgabe. Esse substantivo provém do verbo aufgeben, que significa entregar, em um duplo sentido do termo: dar (geben) algo a alguém para que cuide disso, mas também dar algo a alguém abrindo mão da posse do objeto, como no caso da renúncia de uma cidade entregue ao inimigo. No uso intransitivo do verbo "Ich gebe auf", "eu desisto", "eu renuncio", a segunda acepção do termo é mais forte. Desse modo, a "Aufgabe" do tradutor deve ser compreendida em sua ambivalência: ao mesmo tempo em que é "proposta", "tarefa", "problema a ser resolvido", é também "renúncia" e "desistência". 10

Como pensar essa tarefa, ao mesmo tempo proposta e renúncia, em termos políticos? Como a experiência da tradução, ou de traduzir, pode possibilitar outra maneira de lidar com as identidades historicamente produzidas para as quais as línguas históricas são fundamentais? Traduzir implica sentir-se estrangeiro em sua própria língua e, em oposição ao imperativo da comunicação, implica fazer uma experiência da própria existência da linguagem. É possível o estabelecimento de um laço social a partir do fato de que "há linguagem" para além das línguas históricas? O filósofo italiano Giorgio Agamben, em seus desdobramentos de Walter Benjamin (dentre outros), dedica-se a essas questões. Por isso, para não concluir e para abrir possibilidades de desdobramentos sobre a pergunta que enseja e dá título a este artigo, faço de suas palavras as minhas, pois pode ser que "apesar dos 40 milênios do homo sapiens, a humanidade não tenha ainda se arriscado a fazer a experiência de seu ser falante, a assumir verdadeiramente essa condição de outro modo, que não sob a forma de um Estado ou de uma Nação" (AGAMBEN, 2018, p. 7).

\footnotetext{
${ }^{10}$ Nota do editor da tradução brasileira. (BENJAMIN, 2011a, p. 101).
} 


\section{REFERÊNCIAS}

AGAMBEN, Giorgio. Experimentum linguae: a experiência da língua. Tradução Cláudio Oliveira. Rio de Janeiro: Circuito, 2018.

BENJAMIN, Walter. "Beleza filosófica". A Origem do drama trágico alemão. Tradução João Barrento. Lisboa: Assírio e Alvim, 2004, p.16-19.

BENJAMIN, Walter. O conceito de crítica de arte no romantismo alemão. Tradução Márcio Seligmann-Silva. São Paulo: Edusp, Iluminuras, 1993.

BENJAMIN, Walter. Nähe und Ferne. In: Gesammelte Schriften, vol. IV-1. Frankfurt: Suhrkamp, 1972, p. 9-21.

BENJAMIN, Walter. Para uma crítica da violência. In: BENJAMIN, Walter. Escritos sobre mito e linguagem. Tradução Ernani Chaves. São Paulo: Duas cidades, 2011b. p. 121-156.

BENJAMIN, Walter. Sobre a linguagem em geral e sobre a linguagem do homem. In: BENJAMIN, Walter. Escritos sobre mito e linguagem Tradução Susana Kampff Lages. São Paulo: Editora 34, 2011c. p. 49-73.

BENJAMIN, Walter. Sobre as afinidades eletivas de Goethe. In: BENJAMIN, Walter Ensaios reunidos: escritos sobre Goethe. Tradução Mônica Krausz Bornebusch. São Paulo: Duas Cidades: Editora 34, 2009. p. 11-121

BENJAMIN, Walter. A tarefa do tradutor. In: BENJAMIN, Walter. Escritos sobre mito linguagem. Tradução Susana Kampff Lages. São Paulo: Editora 34, 2011a, p. 101-119 [“Die Aufgabe des Übersetzers", Gesammelte Schriften, v. IV-1, Frankfurt: Suhrkamp, 1972, p. 921].

GAGNEBIN, Jeanne-Marie. A questão de Eros na obra de Benjamin, Revista Artefilosofia, Ouro Preto, n. 4, jan. 2008. p. 39-44.

PINHO, Isabela Ferreira de. O cristal da língua, tagarelar feminino e lalangue em Benjamin e Lacan. In: Benjaminiana: outros ensaios sobre arte, política, linguagem e história. CAMÊLO Francisco; LIMA, Leonardo Apolinário Alves de, BANGE, Patrick Gert; SOUZA, Ricardo Pinto de (org.). São João de Meriti (RJ): Desalinho, 2019, p. 102-120.

PINHO, Isabela Ferreira de. O feminino como medium da linguagem: sobre algumas figuras femininas na obra de Walter Benjamin. Dissertação de mestrado. Orientação Cláudio Oliveira. Coorientação Patrícia Lavelle. Niterói: UFF, 2014.

PINHO, Isabela Ferreira de. Sobre o tagarelar feminino: de Walter Benjamin a Jacques Lacan. Cadernos Walter Benjamin, v. 20, p. 20-36, 2018.

PLATÃO. O Banquete Tradução José Cavalcante de Souza. São Paulo: Abril Cultural, 1972. (Os pensadores). 
SCHMITT, Carl. The nomos of the Earth in the international law of the jus publicum europaeum. Translation G. L. Umen. New York: Telos Press, 2006.

SCHOLEM, Gerschom. Sabatai Tzvi: o messias místico I. Tradução Attílio Cancian, Ari Solon e J. Guinsburg. São Paulo: Perspectiva, 1995. 